\section{Ten Years into Recovery after the Great East Japan Earthquake: Evaluation by Post-2015 Frameworks}

\section{Elizabeth Maly ${ }^{\mathrm{a}^{*}}$}

anternational Research Institute of Disaster Science (IRIDeS), Tohoku University, Sendai Japan

Received: October 2, 2020/ Accepted: January 12, 2021

\section{Abstract}

Devastated by the Great East Japan Earthquake, tsunami, and nuclear meltdown on March 11, 2011, Japan's Tohoku coast has been in the process of disaster recovery for almost a decade. Several international frameworks for disaster risk reduction and sustainable development have also been established during this time. Sharing a holistic approach to comprehensive development principles linking risk reduction, disaster recovery, and development, these three international frameworks are the Sendai Framework for Disaster Risk Reduction 20152020, 2030 Agenda for Sustainable Development 20152030, and the New Urban Agenda. Although each has its own distinct focus, approach, and connection to disaster recovery, the three frameworks share explicit connections and relationships. This paper considers how the first decade of recovery after the GEJE can be evaluated based on the goals and targets from the frameworks in support of people-centered development. After outlining each framework, and exploring the mutual connections between them, aspects relevant to recovery from each are applied to consider issues and progress of housing recovery after the GEJE. Synthesizing multiple aims and goals from the three frameworks relevant to housing recovery creates a more comprehensive tool for evaluation that can identify which goals have been partially or completely achieved. Yet even with the convergence of their respective goals, achieving the overall shared aim of holistic, equitable, and people-centered recovery for all still requires more coordination and consideration of practical applications beyond frameworks.

Keywords: housing recovery; Great East Japan Earthquake; Sendai Framework for Disaster Risk Reduction; SDGs; New Urban Agenda

Abbreviations:
\begin{tabular}{|lll|}
\hline GEJE & $:$ & Great East Japan Earthquake \\
SFDRR & $:$ & Sendai Framework for Disaster Risk \\
& & Reduction \\
SDGs & $:$ & Sustainable Development Goals \\
NUA & $:$ & New Urban Agenda \\
\hline
\end{tabular}

\section{Introduction}

With the massive earthquake that struck on March 11, 2011, the tsunami that devastated Japan's northeast Tohoku coastline, and the nuclear meltdown at the Fukushima Daiichi Nuclear Power Plant (NPP), communities affected by the Great East Japan Earthquake (GEJE) faced extensive and complex recovery challenges over a wide and varied geographical area. For the recovery of the disaster-affected communities, the Japanese national government created a menu of government-funded reconstruction projects, drawing from Japan's past disaster experiences and recovery precedents [1]. Each local municipal government was responsible for choosing from this menu of nationallyfunded reconstruction projects to create their town's recovery plan. As a result, housing reconstruction in most municipalities relied on a combination of these projects, and focused on residential relocation away from tsunami-risk and -inundated areas to new high land areas created by cutting mountains and/or raising the land level (Figs. 1 and 2) [2][3][4].

The primary programs for housing reconstruction were: 1) Collective Relocation for Disaster Mitigation, which funds the acquisition of damaged coastal land and provision of new residential lots in high land areas; and 2) provision of Disaster Recovery Public Housing, which is government-subsidized rental housing for disaster survivors, along with other land readjustment programs [1][5][6][7]. Almost 10 years after the tsunami, reconstruction projects using these programs are nearly finished; provision of new residential lots and public housing is planned to be complete by March 2021 [8].

These and other reconstruction programs have severely altered townscapes and landscapes throughout the entire tsunami-devastated area [2][6][7]. Construction of massive infrastructure including sea walls and levees, hardened coastlines and riverbanks, and highways, has continued nonstop for close to a decade (Figure 3). Massive amounts of soil have been removed from mountains and converted to fill; in some municipalities, it is difficult to recognize any part of the pre-2011 landscape (Figure 4).

\footnotetext{
* Corresponding Author

Tel.: +81-022-752-2153; E-mail: maly@irides.tohoku.ac.jp
} 


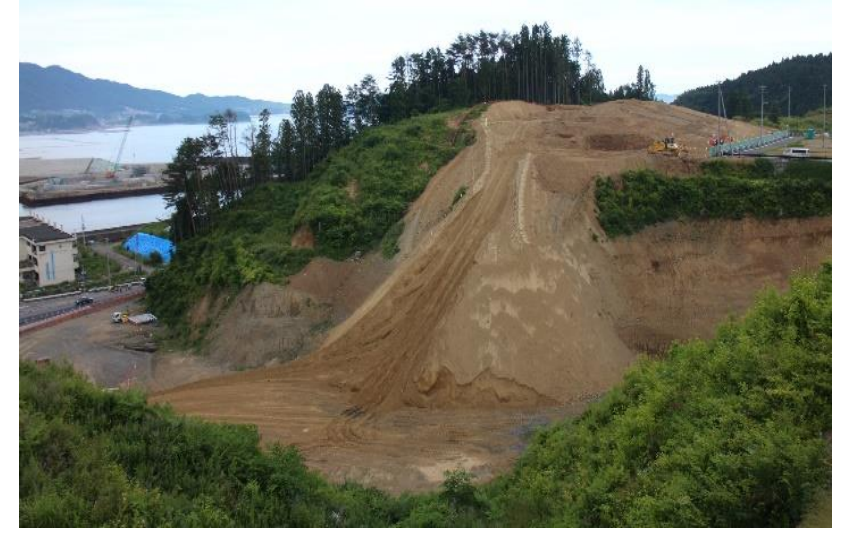

Figure 1 Cut and fill project in Rikuzentakata City.

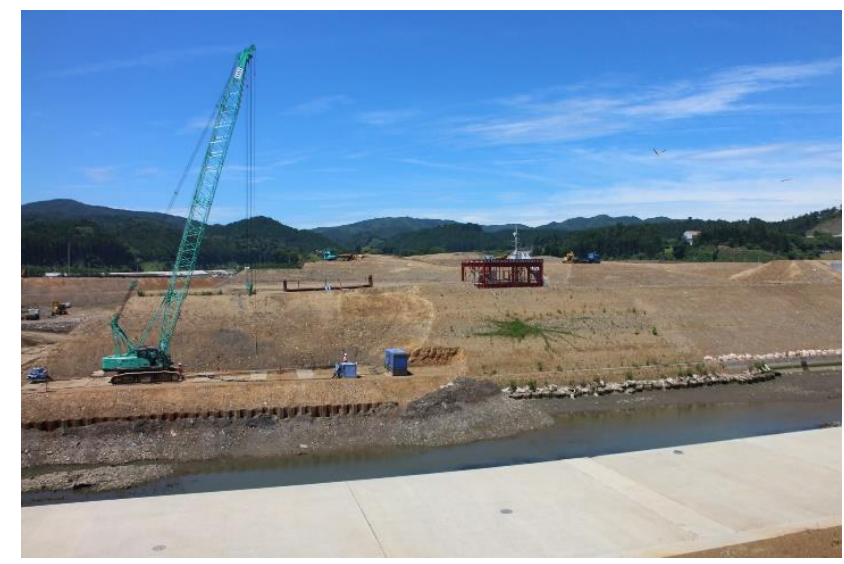

Figure 2 Cut and fill project in Minami Sanriku Town.

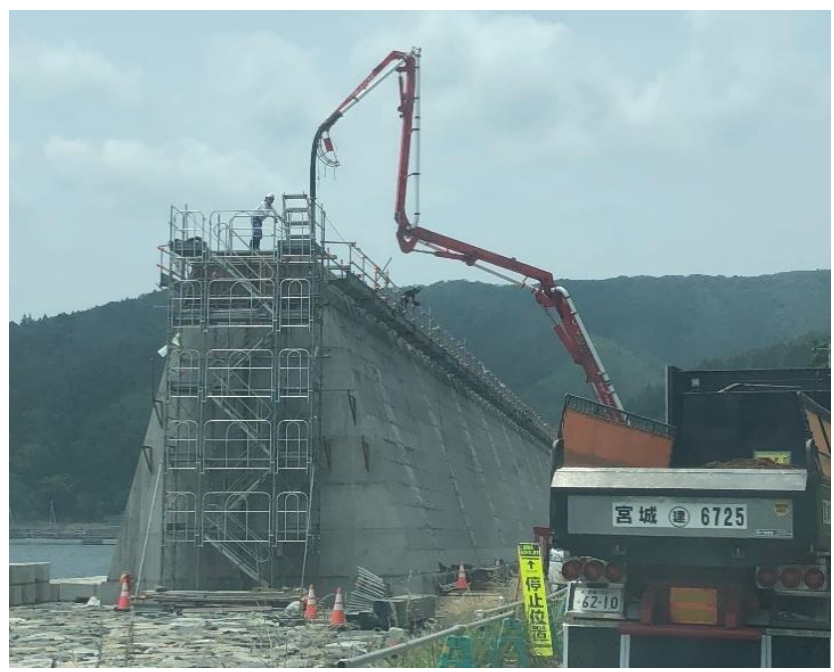

Figure 3 Construction of a coastal levee in Ishinomaki City, an example of infrastructure projects that dominate reconstruction.

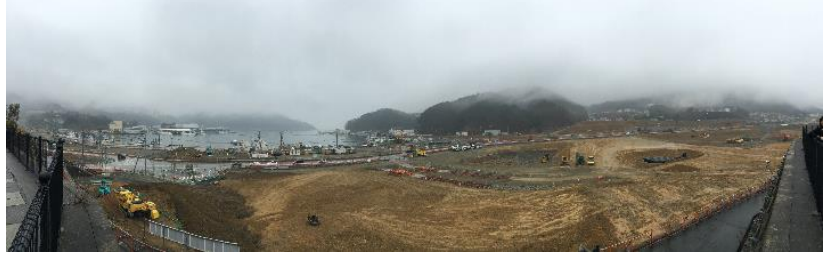

Figure 4 An unfamiliar townscape created by reconstruction in Onagawa Town.

People in communities impacted by radioactive contamination from the nuclear meltdown at the Fukushima Daiichi NPP have experienced chaotic processes of evacuation, fear from unknown risks of radiation, and the loss of former communities and hometowns. Long-term and scattered displacement continues in the face of uncertain futures for the recovery of the affected areas [9][10]. Based on contamination levels, the various designations of evacuation zones have been revised multiple times; the future remains most uncertain for people from the euphemistically named "difficult to return zone" where radiation levels are the highest. In principle, the recovery of affected areas is based on the approach of decontamination through measures such as washing surfaces and scraping and replacing topsoil. Some residents are waiting to return to areas with high levels of contamination; others do not feel safe or wish to return even after evacuation orders are lifted.

The focus of the Japanese government's support for postdisaster housing and community recovery after previous disasters and in tsunami-affected areas after the GEJE is on "hometown recovery." In general, this means evacuation and temporary housing is provided as an interim support measure while residents are waiting to rebuild and move back to former communities. Residential relocation projects, including those used to move many communities away from tsunami-affected coastal areas, are implemented within the boundaries of a single municipality. It is difficult to address the life recovery needs of nuclear evacuees (those displaced because of the nuclear accident) scattered throughout the country. This situation is made more complex by the designation of (and corresponding discrepancies in support for) of evacuees from officially designated evacuation areas (based on contamination measurements) and so-called "voluntary" evacuees from areas that are officially designated as "safe" and/or areas where previous evacuation orders have been lifted. Existing recovery programs struggle to address complex challenges of how to support town reconstruction as well as life recovery of survivors, including the needs of those who continue their lives in displacement as well as those who wish to return to the 12 municipalities near the Daiichi NPP that faced contamination and official evacuation orders. This situation presents unsolvable wicked problems, with no solutions that can replace the loss of hometowns to which people cannot or do not want to return [9].

Several key international frameworks related to disaster risk reduction, sustainable development, and recovery have been adopted in the middle of this first decade of recovery of Tohoku after the GEJE. As the outcome document of the 2015 
3rd World Conference on Disaster Risk Reduction, the Sendai Framework for Disaster Risk Reduction 2015-2020 (SFDRR) can be understood as having had a connection to the ongoing recovery in the Tohoku area. Including the Sustainable Development Goals (SDGs), the 2030 Agenda for Sustainable Development 2015-2030 takes a holistic and comprehensive view of sustainable goals for humanity. Adopted in 2016, the New Urban Agenda synthesizes visions, principles, and commitments to urban sustainability and housing with a rights-based foundation. The three frameworks are similar in their use of specific and measurable goals, targets, and indicators, although they each have their own primary focus on DRR, sustainable development, and urban development, respectively.

With various connections to housing and recovery issues, all three frameworks embrace human security approaches that are people-centered, comprehensive, localized, prevention-oriented, and support people's empowerment. By synthesizing the principles of these three frameworks, this paper considers how the first decade of recovery after the GEJE can be evaluated based on people-centered aspects and applications of guidelines from these frameworks. After introducing their similarities from the perspective of human security, the key aspects of each framework and their mutual connections, relevant aspects are applied to evaluate housing recovery after the GEJE.

\section{Human Security Principles}

\subsection{Human security and housing recovery}

As stated in resolution 66/290 adopted by the United Nations General Assembly 2012 human security recognizes: "the rights of people to live in freedom and dignity, free from poverty and despair," and that all people are "entitled to freedom from fear, freedom from want" [11]. Human security calls for "people-centred, comprehensive, context-specific and prevention-oriented responses that strengthen the protection and empowerment of all people and all communities" [11].

Each of these five principles has direct connections to and implications for post-disaster housing. Long understood in development, emphasis on the first principle of "peoplecentered" approaches to housing has been growing in recent years. Similarly, the need for housing recovery to consider the $2^{\text {nd }}$ and $3^{\text {rd }}$ principles of comprehensiveness (need to consider holistically) and targeted to specific contexts (must be localized) is clear. Although the focus of housing recovery may not always be the $4^{\text {th }}$ principle of prevention-oriented responses, these ideas are often included. Regarding the $5^{\text {th }}$ and final principle, while housing recovery projects may not overtly target the goals of protection and empowerment, securing a context where people are protected and empowered contributes to their ability to carry out disaster reconstruction.

\subsection{Human security principles and integration with international frameworks}

These principles of human security are also reflected in and complementary to the international frameworks of the SFDRR, SDGs, and the NUA. Each of the frameworks highlight and overtly champions their identities as "peoplecentered" frameworks. As each framework emphasizes holistic considerations and interconnectedness of different aspects of people's lives, they also embody the human security principle of "comprehensiveness." A shared focus on detailed targets and goals, as well as measurable indicators, speaks to the human security principle of "localization." Similarly, each framework emphasizes "prevention-oriented responses," as part of a comprehensive consideration of disaster that recognizes the connections between risk reduction, resilience, response, and recovery that is linked to long-term development that mitigates vulnerabilities in society. Overall, these three frameworks demonstrate how key international guidelines are catching up to the human security principles of being "people-centered" and "comprehensive," as each recognizes the rights of people to live with dignity as part of a holistic understanding of disaster risk and recovery integrated with development.

\section{The Sendai Framework for Disaster Risk Reduction (SFDRR) 2015-2030}

\subsection{Background of the SFDRR}

The Sendai Framework for Disaster Risk Reduction 2015-2030 (SFDRR) [12] was adopted as the outcome document of the Third World Conference on Disaster Risk Reduction, in Sendai, Japan in March 2015. As a response to devastating disaster losses, international attention to the importance of disaster risk reduction has been growing over the last several decades; the SFDRR followed two previous precedent international instruments for DRR. The first was the Yokohama Strategy and Plan of Action for a Safer World: Guidelines for Natural Disaster Prevention, Preparedness, and Mitigation [13], the mid-term review of the International Decade for Natural Disaster Reduction (IDNDR) 1989-1999. This was succeeded by the Hyogo Framework for Action 2005-2015: Building the Resilience of National Communities to Disasters (HFA) [14]. Building on the HFA, new aspects of the SFDRR include: 1) practical outcomes and indicators to measure them; 2) localized and people-centered approaches, based on inclusivity and sensitivity to gender, age, (dis)ability, indigenous and vulnerable populations; 3) a crosscutting approach to mainstreaming DRR and emphasizing the interconnectedness of prevention, response, recovery, and development; 4) a strong emphasis on resilience in recovery in the form of the 4 th priority to "Build Back Better" in recovery, rehabilitation, and reconstruction; and 5) specific mentions of climate change and development, education and health, and biological and technical hazards [12,15]. 
The SFDRR includes seven global targets, supported by four priorities for action. Accompanied by detailed goals, the seven global targets are:

a) Reduce disaster mortality

b) Reduce the number of affected people

c) Reduce direct economic losses from disaster

d) Reduce disaster damage to critical infrastructure

e) Increase the number of countries with DRR strategies

f) Enhance international cooperation with developing countries

g) Increase availability and access to early warning systems and disaster risk information and assessments. [12]

The four Priorities for Action in the SFDRR are:

Priority 1: Understanding disaster risk

Priority 2: Strengthening disaster risk governance to manage disaster risk

Priority 3: Investing in disaster risk reduction for resilience

Priority 4: Enhancing disaster preparedness for effective response and to "Build Back Better" in recovery, rehabilitation and reconstruction [12].

\subsection{SFDRR and recovery: Building Back Better}

While its overall focus is holistic disaster risk reduction, the SFDRR mentions several recovery and reconstruction topics including pre-disaster recovery planning; recovery knowledge sharing; land use planning; and reconstruction of community infrastructure [15]. By far the SFDRR's strongest recovery emphasis is Priority Four, which states that the "recovery rehabilitation and reconstruction phase is a critical opportunity to build back better, including through integrating disaster risk reduction into development measures" [12, 15]. The slogan of Building Back Better (BBB) had been gaining popularity since it was used following the 2004 Indian Ocean Tsunami $[16,17,18]$, yet the term is open to multiple interpretations of what is "better." In some cases, the term is used with a reductive focus on building back safer through physical infrastructure measures without considering holistic or even negative impacts on peoples' lives and livelihoods $[15,16,19,20,21]$.

Leading up to the Third World Conference on Disaster Risk Reduction, the Japanese government strongly promoted the inclusion of "Build Back Better" in the SFDRR [22]. As presented by the Japanese government, this was part of a strategy to showcase 'successful BBB practices' in post-GEJE recovery [22]. This message, equating Japanese recovery with building back better, is also tied to the exporting of 'advanced' knowledge to other (especially developing) countries, a well-established part of Japan's disaster diplomacy, linked to international aid and development projects under the Japanese International Cooperation
Agency (JICA) [23]. Combining disaster risk reduction and international development, JICA has fully embraced the slogan of BBB with public and vocal support for exporting lessons from Japanese disaster and recovery experience to developing countries [23,24,25].

The inextricable connections for Japan between BBB, JICA, international development, and DRR in developing countries are highlighted by an English article from the Government of Japan's own PR Office, which defines BBB as the "concept of rebuilding an affected area to a state that is stronger against disasters than it was before the disaster" [25]. As JICA projects also have a strong focus on physical infrastructure, this attitude epitomizes the risk of the term BBB being deployed and potentially misunderstood as solely rebuilding strong infrastructure without holistically considering the needs of affected people $[16,19,20,21]$.

Although it does not address all the needs of disasteraffected residents for recovering their lives and livelihoods, building back safer and stronger is also an important part of DRR in recovery, and a meaningful part of $\mathrm{BBB}$, as has been discussed by Fan [20] and Kennedy [21]. More recently, the Global Facility for Disaster Risk Reduction (GFDRR) has presented a more nuanced understanding of the concept of Building Back Better that encompasses building back stronger, building back faster, and building back more inclusively [26].

\subsection{SFDRR and GEJE recovery}

Recovery after the GEJE can be understood as having achieved some of the goals of the SFDRR, especially through projects related to physical reconstruction, including land use planning (Priority 4, 33(j) and $33(\mathrm{k})$ ); relocation of critical facilities outside hazardous areas (Priority 4, 33(l); and resilience of new facilities (Priority 4, 33(c) ) [15]. Some goals for recovery in the SFDRR can be considered partially achieved, such as the provision of psychological care (Priority 4, 33(o), while other aspects supported by the SFDRR have not been achieved, including the empowerment of women and people with disabilities to publicly lead and promote gender equity and universal accessibility (Priority 4, 32) [15].

The degree to which recovery in Tohoku reflects the 7 global targets of the SFDRR differs greatly between areas affected by tsunami and/or nuclear disaster. Post-tsunami projects that focus on infrastructure reconstruction and residential relocation can be expected to achieve goals a) substantially reduce disaster mortality, b) substantially reduce the number of affected people, and c) reduce direct economic losses from disaster. However, considering the same three goals in the context of the nuclear disaster, the result is the opposite. Along with the long-term displacement of nuclear evacuees, the number of lives lost later or from indirect causes (including from the evacuation process and later impacts) in Fukushima is greater than the number of people who were killed directly by earthquake or tsunami. As highlighted by Fukushima Booklet Committee [27], within the long-term disruption of lives as well as economic 
prosperity, considering these three goals shows increased disaster mortality, an increased number of affected people (and the length of time they are affected), and increased economic losses for nuclear disaster-affected areas[15][27].

\section{Transforming our world: the 2030 Agenda for Sustainable Development and Sustainable Development Goals (SDGs)}

\subsection{Background of the 2030 Agenda and SDGs}

With the goal of "leaving no one behind," Transforming Our World: The 2030 Agenda for Sustainable Development was adopted by the United Nations General Assembly in September 2015. Including the 17 Sustainable Development Goals (SDGs) supported by 169 specific targets, the 2030 Agenda represents the first comprehensive vision of development with clear goals and targets. The Sustainable Development Goals SDGs follow the Millennium Development Goals (MDGs), whose eight goals on "hunger, disease, unmet schooling, gender inequality, and environmental degradation" guided international efforts to fight poverty from 2000-2015 [28]. First suggested in the 2012 report "The Future We Want" [29], the following 17 Sustainable Development Goals are "universal, indivisible and interlinked" [30].

Goal 1. End poverty in all its forms everywhere

Goal 2. End hunger, achieve food security and improved nutrition and promote sustainable agriculture

Goal 3. Ensure healthy lives and promote well-being for all at all ages

Goal 4. Ensure inclusive and equitable quality education and promote lifelong learning opportunities for all

Goal 5. Achieve gender equality and empower all women and girls

Goal 6. Ensure availability and sustainable management of water and sanitation for all

Goal 7. Ensure access to affordable, reliable, sustainable and modern energy for all

Goal 8. Promote sustained, inclusive and sustainable economic growth, full and productive employment and decent work for all

Goal 9. Build resilient infrastructure, promote inclusive and sustainable industrialization and foster innovation

Goal 1o. Reduce inequality within and among countries

Goal 11. Make cities and human settlements inclusive, safe, resilient and sustainable

Goal 12. Ensure sustainable consumption and production patterns
Goal 13. Take urgent action to combat climate change and its impacts

Goal 14. Conserve and sustainably use the oceans, seas and marine resources for sustainable development

Goal 15. Protect, restore and promote sustainable use of terrestrial ecosystems, sustainably manage forests, combat desertification, and halt and reverse land degradation and halt biodiversity loss

Goal 16. Promote peaceful and inclusive societies for sustainable development, provide access to justice for all and build effective, accountable and inclusive institutions at all levels

Goal 17. Strengthen the means of implementation and revitalize the global partnership for sustainable development [31].

\subsection{Mutual connections between SDGs and SFDRR}

The 2030 Agenda reflects the importance of risk reduction for sustainable development, as it directly references the SFDRR, sets targets for DRR, and adopts common indicators [31]. As emphasized in the 2019 Global Assessment Report on Disaster Risk Reduction (GAR), unlike their respective predecessors the MDGs and HFA, the SDGs and SFDRR are linked by the recognition that achieving their objectives requires mutually dependent "risk-informed sustainable development" [32]. Including a UNISDR reflection paper, "Disaster risk reduction and resilience in the 2030 agenda for sustainable development," multiple publications have considered the SDGs through the lens of the SFDRR and their overlapping and related aspects [33].

In addition to specific mentions of the SFDRR, multiple goals and targets in the 2030 Agenda focus directly on DRR, such as reducing the vulnerability of poor people to disasters or building more resilient infrastructure [31]. Other goals and targets also contribute to reducing risk and/or building resilience, such as improving educational opportunities and health [31]. Concerning disaster recovery, several Targets of Goal 11 are directly linked to ideas and approaches outlined in the SFDRR, including SDG Target 11.5) By 2030, significantly reduce the number of deaths and the number of people affected and substantially decrease the direct economic losses, which overlaps with SFDRR global targets: a) Substantially reduce disaster mortality; b) Substantially reduce the number of affected people and c) Reduce direct economic losses from disaster [12]. SDG Target 11.b calls for the implementation of integrated policies and plans towards inclusion, resource efficiency, mitigation and adaptation to climate change, resilience to disasters, and develop and implement...holistic disaster risk management at all levels, overlapping SFDRR global target e) Increase the number of countries with DRR strategies. SDG Target 11.b specifically mentions that these efforts should be "in line with the Sendai Framework for Disaster Risk Reduction 2015-2030" [31]. 


\subsection{SDGs and targets and recovery}

Goal 11. Make cities and human settlements inclusive, safe, resilient and sustainable directly connects to post-disaster housing and community recovery; the other 16 goals relate to aspects of recovery as part of three overlapping groups: livelihood (goals 8, 1, 2, 4, 5, 9, 13, 14); health (goals 3, 1, 2, 4, 5 , 6); the environment (goals 15, 6, 7, 12, 13, 14) and overarching equality goals $(10,16,17)$. Targets included in Goal 11 directly applicable to housing recovery include: ensuring that everyone has access to adequate, safe, and affordable housing (target 11.1); the construction of sustainable and resilient buildings utilizing local materials (target 11.c); and relating recovery to risk reduction, adopting and implementing integrated policies and plans towards inclusion, resource efficiency, mitigation and adaptation to climate change, resilience to disasters (target 11.b). Targets at the scale of settlements include sustainable transport systems (target 11.2); universal access to safe, inclusive and accessible, green and public spaces (target 11.7); and links between urban, peri-urban, and rural areas by strengthening development planning (target 11.c) [31].

\subsection{SDGs and Tohoku recovery}

As in the previous discussion about the SFDRR, regarding SDGs and targets for disaster risk reduction, post-GEJE recovery measures that focused on massive infrastructure and landscape modification combined with large scale housing relocation contribute to achieving targets 11.5, significantly reduce the number of deaths, people affected and direct economic losses caused by disasters and 11.b, increase resilience to disasters, and develop and implement, in line with the Sendai Framework for Disaster Risk Reduction 2015-2030, holistic disaster risk management at all levels.

Goal 11 and related targets can be a useful way to consider and evaluate ongoing recovery in Tohoku after the GEJE. Japan's policy of providing Disaster Recovery Public Housing (government-subsidized rental public housing to disaster survivors) supports target 11.1, access for all to adequate, safe and affordable housing (Fig. 5 and Fig. 6). With Tohoku's forestry resources and timber building culture, the use of wood for temporary housing (Fig. 7) and permanent housing construction supports target 11.c, building sustainable and resilient buildings utilizing local materials.

Spatial planning aspects of town recovery in Tohoku encompass the aims of target 11.7, provide universal access to safe, inclusive and accessible, green and public spaces. Although recovery plans were intended to follow the aims of target 11.a, support positive economic, social and environmental links between urban, peri-urban and rural areas by strengthening national and regional development planning, the reality 10 years after the tsunami varies between communities in terms of what level of development planning has been achieved. Considering target 11.3 inclusive and sustainable urbanization and capacity for participatory, integrated and sustainable settlements, the levels of inclusivity and participation in settlement recovery

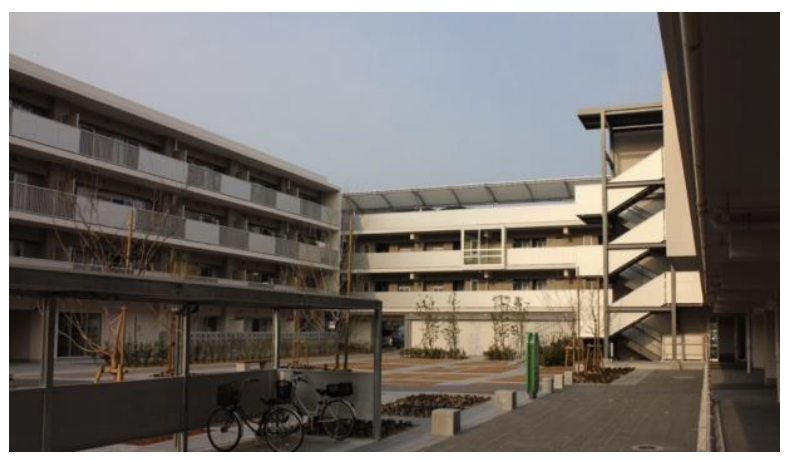

Figure 5 Multifamily type disaster recovery public housing in Onagawa Town.

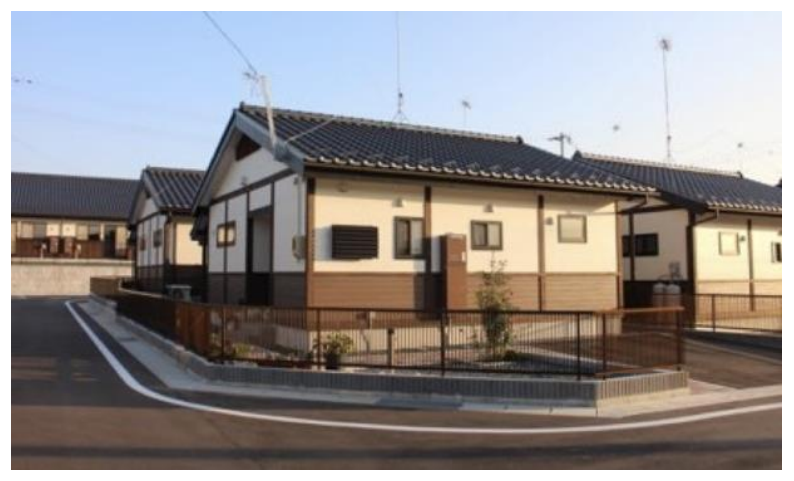

Figure 6 Single family type disaster recovery public housing in Minami Soma Town.

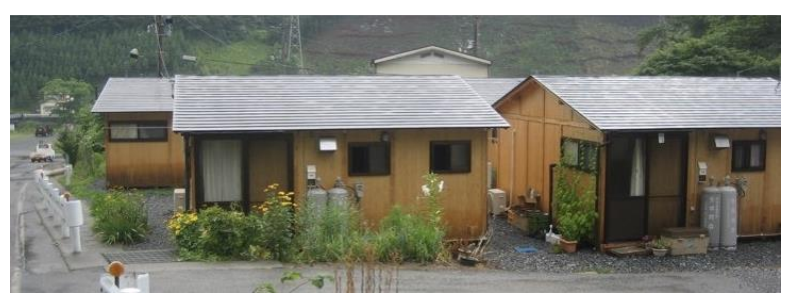

Figure 7 Wooden temporary housing in Sumida Town. 


\section{The New Urban Agenda (NUA)}

\subsection{The NUA connections to SFDRR and SDGs}

Adopted in October 2016 at the United Nations Conference on Housing and Sustainable Urban Development (Habitat III) in Quito, Ecuador, the New Urban Agenda (NUA) is closely connected to and explicitly acknowledges both the 2030 Agenda and the SFDRR [34]. The NUA shares the broad commitments to inclusivity of the 2030 Agenda and DRR and resilience of the SFDRR for an urban context. Promoting sustainable urban development and representing issues of disaster risk, resilience, and sustainability as they are magnified and amplified in the urban context, the NUA shares broader goals for sustainable development and the aim to "leave no one behind" of the 2030 Agenda [31][34]. Situated as contributing to the "implementation and localization of the 2030 Agenda...in an integrated manner," the NUA includes direct connections to aims of Goal 11 of the SDGs on sustainable communities and cities [34]. Like the mutually interconnected SDGs, the 'transformative commitments' of the NUA aim to "harness the potential of sustainable urban development" through an "urban paradigm shift grounded in the integrated and invisible dimensions of sustainable development: social, economic, and environmental" [34].

Referred to as the "right to the city," the NUA champions a vision of cities for all, with the equal use and enjoyment of cities and human settlements, and seeks to promote inclusivity and ensure that all inhabitants of present and future generations, without discrimination of any kind, can inhabit and produce just, safe, healthy, accessible, affordable, resilient and sustainable cities and human settlements to foster prosperity and quality of life for all [34]. Sharing commitments of the SFDRR and 2030 Agenda to improve the world for the benefit of humankind, the NUA is more overtly based on principles of rights and freedom, stating "we aim to achieve cities and human settlements where all persons are able to enjoy equal rights and opportunities, as well as their fundamental freedoms, guided by the purposes and principles of the Charter of the United Nations, including full respect for international law" [34]. With this grounding in the Universal Declaration of Human Rights, the NUA is closer to the rights-based approach of human security, champions rights to adequate housing, and is emphatically "universal in scope, participatory and people-centered" [34]. The NUA is based on statements of shared Visions for cities and settlements that include universal access along with the right to adequate housing; participation; gender equality and empowerment; sustainable economic growth; accessible urban mobility; disaster resilience and climate change adaptation and protection and conservation of ecosystems [34]. Next, the NUA's Principles embrace ending poverty; ensuring sustainable and inclusive urban economies as well as environmental sustainability. Following a call to action to implement the NUA as a key instrument to achieve sustainable urban development, the majority of the NUA is made up of detailed 'transformative commitments' to social, economic, and environmental aspects of sustainable urban development. A comprehensive explanation of relationships of aspects of the NUA and SDGs has been created and made available by Compass Housing Services [35].

\subsection{NUA and Tohoku recovery}

NUA commitments related to housing recovery can be grouped by themes of housing rights; settlement features/amenities; participation/inclusivity; social vulnerability; and DRR. These thematic categories can be used to consider the ongoing housing recovery in Tohoku, and evaluate various aspects and the degree to which they represent the equity and rights-based approach of the NUA.

\subsubsection{Housing rights and recovery}

Like SDG Target 11.1, the NUA strongly supports the right to housing, through commitment 31) promoting housing policies that support the progressive realization of the right to adequate housing for all and 46) promoting the role of affordable and sustainable housing and housing finance, including social habitat productions, in economic development [34]. As mentioned previously regarding SDG targets 11.1 and 11.c, Japanese policies providing public housing for disaster survivors and the use of local building materials and local companies support these commitments.

However, considering commitment 77 ) retrofitting all risky housing stock, to make it resilient to disasters, although overall Japanese housing policies provide high-quality housing to the most vulnerable members of society through public housing, after the GEJE a new challenge emerged in the form of zaitaku hinansha, or people who stayed in their damaged home and did not qualify for repairs (or did not know how to access or choose from existing support programs) or new housing. This situation shows a weakness of Japan's housing recovery policy, which does not address the needs of all disaster survivors. For evacuees from the nuclear disaster, Japan's approach to post-disaster reconstruction focusing on 'hometown recovery' is limited in addressing the needs of people still facing long-term and scattered displacement from their former homes [9][10].

In addition, from the point of view of international human rights, commitment 28) ensuring full respect of the human rights of refugees, internally displaced persons and migrants raise issues that have yet to be addressed for evacuees from areas affected by the nuclear meltdown at the Fukushima Daiichi NPP. There has been no acknowledgment that these nuclear disaster evacuees, displaced from their hometowns to other parts of Japan, are in fact Internally Displaced Persons (IDPs) and as such entitled to all international protections and rights [9][10][36]; this is the case even though many organizations have been doing legal and human rights advocacy around this issue [36]. 


\subsubsection{Settlements and recovery}

NUA's focus on settlements is highlighted by commitments 34) promoting equitable and affordable access to sustainable basic physical and social infrastructure for all, including affordable serviced land, housing and 37) safe, inclusive, accessible, green and quality public spaces, as well as 67) open spaces that contribute to the resilience of cities to disasters and climate change. As mentioned previously in regard to SDG target 11.7, reconstruction projects in Tohoku have successfully created parks and open spaces, as well as a high level of urban infrastructure, which is not surprising in Japan, a wealthy country with routine and massive investment in engineering and infrastructure projects.

NUA calls for compact city planning and control of urban sprawl in commitments 97) 98) and 106). While recovery planning in some of the small cities in the Tohoku region incorporated ideas of compact city planning, facing delays in implementation of housing recovery projects many people who had the financial resources moved and rebuilt on their own. As explained by Kondo [6] and Kondo and Karatani [7], this resulted in lower density sprawl in multiple municipalities.

In light of NUA commitment 69) promoting the ecological and social function of land, including coastal areas, the revitalization of coastal regions after they have been reshaped by not only the tsunami but also by recovery projects which separate and in many cases distance residential from other uses, create unresolved questions for long-term sustainable development in the region.

\subsubsection{Participation/inclusivity, social vulnerability, and recovery}

Multiple NUA commitments emphasize participation and inclusion, linked to social vulnerability, such as: 26) urban and rural development that is people-centered, protects the planet, and is age- and gender-responsive and supports the realization of all human rights and fundamental freedoms... empowering all individuals and communities while enabling their full and meaningful participation; 27) pledging that no one will be left behind;32) development of integrated and ageand gender-responsive housing policy and approaches across all sectors; 33) housing options that are safe, affordable, and accessible for members of different income groups of society; 34) services that are responsive to the rights and needs of women, children and youth, older persons and persons with disabilities, 41) mechanisms to broaden inclusive platforms that allow meaningful participation in decision-making, planning and follow up processes for all, as well as civic engagement and co-provisions and co-production, and 42) strengthening the interface for all dialogues, including through age- and gender-responsive approaches and with particular attention to contributions from all segments of society, including men and women, children and youth, older persons and persons with disability [34].

Although the recovery planning processes used after the GEJE included the participation of residents to varying degrees, this differed greatly depending on the local area. Traditional hierarchical and patriarchal structures in both government and local communities tended to exclude women and younger people from decision-making processes in favor of elderly men [40]; these and other local historical and social contexts, as well as decision-making timescales and implementation methods, meant that not all voices were equally expressed or heard.

The Tohoku region is experiencing the effects of a rapidly aging population [41], a critical issue of social vulnerability highlighted by NUA commitment 62) addressing the social, economic and spatial implication of aging populations ...harnessing the aging factor as an opportunity for new decent jobs and sustained, inclusive and sustainable economic growth, while improving the quality of life of the urban population [34]. Thinking of the large number of elderly residents in Tohoku and the growing needs that accompany their aging, recovery projects provided not only housing but other social infrastructure such as hospital facilities. In addition to government-led projects, community and nonprofit organizations have also focused on improving the lives of the elderly. One such example is the ibasho project. Based on the Japanese concept and word iibasho which means "a place where you can feel like yourself" in Japanese [42], the first ibasho project was established in 2012 in a tsunamiaffected community in Tohoku. With principles of elder empowerment and community building, the Ibasho House functions as a community space managed for and by elderly residents [42]. However, housing recovery and relocation projects which created many isolated and dispersed singleuse residential settlements in high land areas across the Tohoku region do not adequately address the short, medium, or long-term needs of aging communities [6][7][9]

\subsubsection{DRR and recovery}

DRR is the focus of NUA commitment 77) strengthening the resilience of cities and urban settlements, including through the development of quality infrastructures and spatial planning, by adopting and implementing integrated age- and gender-responsive policies and plans and ecosystem-based approaches in line with the SFDRR and by mainstreaming holistic and data-informed disaster risk reduction and management at all levels to reduce vulnerabilities and risk. Commitment 78) also supports moving from reactive to more proactive risk-based, all hazards and all of society approaches.

This approach supports the integration of "build back better" principles into the post-disaster recovery processes, integrating resilience-building, environmental and special measures and lessons from past disasters, as well as awareness of new risks, into future planning. However, as mentioned previously in regard to SFDRR and post-GEJE recovery, evaluation of recovery outcomes diverges based on which interpretation of "build back better" is used. It is easy to claim that "building back better" has been achieved in the case of reconstruction that focuses exclusively on the creation/strengthening of infrastructure and physical relocation outside of designated risk areas. However, with a 
more holistic consideration of what is really "better" for disaster survivors and their life recovery, it is more difficult to conclude the reconstruction of stronger infrastructure is equal to building back better.

\section{Summary of key commonalities}

Each of the three international frameworks has its own distinct focus, along with a shared commitment to comprehensive development principles linking risk reduction, disaster recovery, and development. In addition to the explicit and stated connections linking the frameworks, there are similarities and overlapping points within and across the global targets and priorities of the SFDRR, the goals and targets of the SDGs, and the commitments of the NUA, as previously discussed in section 4.2 and 5.1. Table 1 compares the key shared aspects and similarities across the aims (priorities/goals/targets/commitments, respectively) of the frameworks. As shown in Table 1, the goals/priorities of the SFDRR and goals/targets of the SGDs share a strong focus on the reduction of disaster losses. Within the conceptualization of urban and spatial resilience towards this aim, the priorities of the SFDRR focus on concrete actions, while the relevant aims of the NUA and SDGs present a more holistic and comprehensive approach. As Table 1 also shows, for topics related to housing, spatial design, planning, and urbanization, there are multiple closely overlapping aspects of specific targets related to Goal 11 of the SDGs and the NUA commitments.

As discussed in sections 3.2, 3.3, 4.3, 44, and 5.2, the three frameworks have various applications to disaster recovery in general as well as post-GEJE recovery in Tohoku. Table 2 highlights the degree to which key goals/priorities/targets/commitments for recovery of the three frameworks have been achieved in Tohoku. Overall, targets for safer and stronger physical reconstruction and infrastructure have been met, while spatial and community level planning goals have been partially achieved. However, there are several unmet goals related to empowerment, equity, and human rights. In addition, some recovery goals achieved in tsunami-affected areas have not been met for communities affected by the nuclear disaster. Almost ten years after the GEJE, this discrepancy highlights the need to address the complex and severe ongoing recovery challenges that remain for nuclear disaster-affected communities and others whose needs are not addressed by recovery programs. In addition, although many specific and concrete measures have been achieved in reconstruction projects, holistic consideration for future needs of local communities and society have received less attention.

\section{Conclusion}

These three international frameworks, the Sendai Framework for Disaster Risk Reduction (SFDRR) 2015-2030, the 2030 Agenda for Sustainable Development 2015-2030, and New Urban Agenda (NUA) represent compatible conceptualizations of and approaches to disaster risk reduction, recovery, and development. Created on a similar timeline, and referencing and complementing each other, they share the goal to improve the quality and dignity of human life within our global society.

\subsection{Complementary frameworks and goals}

Although risk reduction is the main focus, the role of recovery features prominently in the SFDRR, which strongly supports connections between DRR, recovery, and development. Considering the 2030 Agenda for Sustainable Development from the point of view of DRR, each goal for sustainable development can be inversely understood as contributing to a reduction in risk. Based on the principles of human rights, housing rights, and rights to the city, the New Urban Agenda represents a slightly different perspective. Yet the 2030 Agenda and SDGs reflect similar ideas as part of a focus on equality and dignity. The key ideas and slogans of the frameworks are also complementary and compatible: Building Back Better (from the SFDRR); Leaving no one behind (in the SDGs); and the Right to the City (of the NUA).

\subsection{Limitations and potential of frameworks for evaluation}

Although the frameworks share holistic commitments to people-centered approaches and empowered communities, even if their more detailed targets are completely or partially achieved, this does not guarantee the successful achievement of the overall goals. Synthesizing multiple aims/goals from the three frameworks relevant to recovery can create a more comprehensive tool for evaluation. However, several critical points emerge from this analysis.

By starting from the goals of the frameworks and then matching relevant examples from ongoing recovery cases, evaluation is limited to a mesh-like instrument. As attention will only be drawn to achievements (or their lack thereof) that closely match a specific target or goal, there is a chance that critical aspects needed to support the fundamental goals of people-centered recovery may be overlooked if they are not represented by a specific goal or aim within the frameworks. As other experts have discussed, along with the proliferation of international frameworks, it will still be necessary to improve their coordination, even with their convergence, and move beyond frameworks towards practical application and achievements [37][38][39]. As a framework is only as useful to the degree to which it can shape and improve the reality on the ground, additional evaluation of these frameworks and their myriad and mutual connections to recovery impacts is still needed. Localized case studies might be a more effective approach to consider the implementation of the principles of these post-2015 frameworks.

The application of these frameworks to analyze the housing recovery processes and outcomes represents a somewhat uncommon approach, as development frameworks are less often applied to housing reconstruction projects. The global and/or universal applicability of development frameworks is also less likely to be considered 
in the context of a wealthy country (like Japan), where development may be conceptualized as international aid to help other people in poor countries. Therefore, although applying the detailed goals synthesized from these three key international frameworks is an incomplete and imperfect method for the evaluation of recovery, it can be an effective way to leverage universal and rights-based approaches to consider recovery processes in wealthy countries and highlight areas where further attention is needed.

\section{References}

[1] Iuchi K, Maly E, and Johnson L. Three Years After a Megadisaster: Recovery Policies, Programs, and Implementation After the Great East Japan Earthquake. In Santiago-Fandino, V, Kontar Y, Kaneda Y, editors. Post-Tsunami Hazards Reconstruction and Restoration, Cham: Springer; 2015, p. 29-46.

[2] Araki Y et al. The Great East Japan Earthquake and Tsunami: Lessons for land use. In Banba M and Shaw R, editors. Land Use Management in Disaster Risk Reduction: Perspectives and Cases from a Global Perspective, Tokyo: Springer; 2017.

[3] Iuchi K. Disaster risk management and its relationship to landuse geographies vulnerable to water-related disasters: An analysis of the Japanese legislative system. In Greiving $\mathrm{S}$ et al, editors. Spatial Planning and Resilience Following Disasters: International and Comparative Perspectives, Bristol: Policy Press; 2016.

[4] Ubaura M. Changes in land use after the Great East Japan Earthquake and related issues of urban form. In SantiagoFandino $\mathrm{V}$ et al, editors. The 2011 Japan earthquake and tsunami: Reconstruction and restoration, Cham: Springer; 2018.

[5] Iuchi K and Olshansky R. Revisiting Tohoku's 5-Year recovery: Community rebuilding policies, programs and implementation. In Santiago-Fandino V et al, editors. The 2011 Japan earthquake and tsunami: Reconstruction and restoration, Cham: Springer; 2018.

[6] Kondo T. Planning challenges for housing and built environment recovery after the Great East Japan Earthquake: Collaborative planning and management go beyond government-driven redevelopment projects. In Santiago-Fandino V et al, editors. The 2011 Japan earthquake and tsunami: Reconstruction and restoration, Cham: Springer; 2018.

[7] Kondo T and Karatani Y. Spatial planning for housing recovery after the Great East Japan Earthquake. In Greiving S, et al, editors. Spatial planning and resilience following disasters: International and comparative perspectives, Bristol: Policy Press; 2016.

[8] Japan Reconstruction Agency. Current situation and challenges of reconstruction; 2020.

https://www.reconstruction.go.jp/topics/main-cat1/sub-cat11/material/2020.4_genjoutokadai.pdf. Accessed 5 August 2020.

[9] Maly E. People centered housing recovery in Tohoku. In Hobsen $\mathrm{C}$ and Bacon P, editors. Human Security and Disasters. Tokyo: Routledge; 2014, p. 33-62.

[10] Maly E. Housing Recovery and Displacement from Fukushima: Five Years Post-Nuclear Meltdown. In Santiago-Fandino V et al, editors. The 2011 Japan earthquake and tsunami: Reconstruction and restoration, Cham: Springer; 2018.

[11] United Nations General Assembly (UNGA), Resolution adopted by the General Assembly on 10 September 2012; 2012. https://documents-dds-
ny.un.org/doc/UNDOC/GEN/N11/476/22/PDF/N1147622.pdf?O penElement. Accessed 26 November 2020.

[12] UNISDR. Sendai Framework for Disaster Risk Reduction 20152030; 2015 . http://www.unisdr.org/files/43291_sendaiframeworkfordrren.p df. Accessed 26 November 2020.

[13] IDNDR. Yokohama Strategy and Plan of Action for a Safer World: guidelines for natural disaster prevention, preparedness and mitigation; 1994.

https://www.unisdr.org/we/inform/publications/8241

[14] UNISDR. Hyogo Framework for Action (HFA) 2005-2015: Building the Resilience of Nations and Communities to Disasters; 2005.

[15] Maly E, and Suppasri A. The Sendai Framework for Disaster Risk Reduction at Five: Lessons from the 2011 Great East Japan Earthquake and Tsunami. International Journal of Disaster Risk Science 2020 11(2): 167-178.

[16] Maly E. Building back better with people centered housing recovery. International Journal of Disaster Risk Reduction 2018; 29: 84-93.

[17] ClintonWJ. Lessons Learned from Tsunami Recovery: Key Propositions for Building Back Better, United Nations SecretaryGeneral's Special Envoy for Tsunami Recovery, United Nations, New York; 2006.

[18] James Lee Witt Associates. Building Back Better and Safer: Private Sector Summit on Post-Tsunami Reconstruction, James Lee Witt Associates: Washington, DC; 2005.

[19] Monday JL. Building back better: creating a sustainable community after disaster. Nat. Hazards Inf. 2002; 3. 1-12

[20]Fan L. Disaster as Opportunity? Building Back Better in Aceh, Myanmar and Haiti, Overseas Development Institute; 2013.

[21] Kennedy J, Ashmore J, Babister E, and Kelman I. The Meaning of 'Build Back Better': Evidence From Post-Tsunami Aceh and Sri Lanka, J. Contingencies Crisis Manag 2008; 16(1): 24-36,

[22] Cabinet Office of Japan. White Paper: Disaster Management in Japan 2015; 2015. http://www.bousai.go.jp/kyoiku/panf/pdf/WP2015_DM_Full_V ersion.pdf. recovery

[23] Yamada Y and Clausen D. Chapter 8: Risk Management Disaster Diplomacy and the Struggle for National Identity in Japan. In. Maslow S, Mason R, and O'Shea P, editors. Risk State: Japan's Foreign Policy in an Age of Uncertainty, Ashgate Publishing, Surrey, England: Ashgate Publishing Limited; 2015.

[24] Sawaji O. Disaster Risk Reduction: Japan's International Contribution, the Japan Journal; 2020.

[25] Sawaji O. Building the World Back Better, Public Relations Office, the Government of Japan; 2020. https://www.gov- 
online.go.jp/eng/publicity/book/hlj/html/202006/202006_o8_e n.html

[26]GFDRR. Building Back Better: Achieving resilience through stronger, faster, and more inclusive post-disaster reconstruction; 2018.

[27] Fukushima Booklet Committee. Japan's Dilemma: Nuclear power plant accident and implementation of Sendai Framework for DRR; 2018. http://fukushimalessons.jp/en-booklet.html.

[28] Sachs, JD. From Millennium Development Goals to Sustainable Development Goals. The Lancet. June 09, 2012.

[29]17 goals. Story behind the goals; 2015. http://17goals.org/thestory-behind-the-goals/

[30] UNDP. Background on the goals; 2015. https://www.undp.org/content/undp/en/home/sustainabledevelopment-goals/background.html

[31] UN General Assembly. Transforming our world: the 2030 Agenda for Sustainable Development, A/RES/70/1; 21 October 2015.

[32] https://www.refworld.org/docid/57b6eze44.html. Accessed 1 October 2020.

[33] UNDRR. Global Assessment Report on Disaster Risk Reduction. Geneva, Switzerland: United Nations Office for Disaster Risk Reduction (UNDRR); 2019.

[34] UNISDR. Disaster risk reduction and resilience in the 2030 agenda for sustainable development, a reflection paper; 2015.

[35] United Nations. New Urban Agenda, New York: United Nations; 2017. https://habitat3.org/the-new-urban-agenda. Accessed 30 November 2020.

[36] Compass Housing Services. Linking the SDGs with the New Urban Agenda; 2017.

[37] www.sdgsnewurbanagenda.com/home.html

[38] Hasegawa R. Returning Home after Fukushima? Displacement from a Nuclear Disaster and International Guidelines for IDPs. IOM Migration, Environment and Climate Change: Policy Brief Series IOM, Geneva; 2015: 4(1).

[39] Kelman I. Linking disaster risk reduction, climate change, and the sustainable development goals. Disaster Prevention and Management: An International Journal 2017; 26(3), p.254-258.

[40]Murray V et al. Coherence between the Sendai Framework, the SDGs, the Climate Agreement, New Urban Agenda and World Humanitarian Summit, and the role of science in their implementation. Conference paper presented at the Global Platform for Disaster Risk Reduction 2017.

[41] Sandholz S et al. Costs and benefits of (in)coherence: Disaster Risk Reduction in the Post-2015-Agendas. Synthesis Report. Bonn: United Nations University - Institute for Environment and Human Security (UNU-EHS); 2020.

[42] Kaneko Y. Lessons from the 2011 East Japan Earthquake: issues of participation and early recovery. In Kaneko Y, Matsuoka K, and Toyoda T, editors, Asian Law in Disasters: Toward a HumanCentered Recovery; 2016, p. 34-78.

[43] Kuwajima K. Aging in the Tohoku District, Japan, Annals of The Tohoku Geographical Association 1989; 41(2): 120-127.

[44] Iibasho; 2020. https://ibasho.org/ Accessed 30 November 2020. 
Table 1 Shared commonalities among the detailed targets, priorities, goals and commitments of the three frameworks.

\section{SFDRR}

Global targets:

a) Substantially reduce disaster mortality

b) Substantially reduce the number of affected

people

c) Reduce direct economic losses from disaster

Global target e) Increase the number of countries with DRR strategies

Priority 4, 33(j) and 33(k)): Land use planning

Priority 4, 33(l): relocation of critical facilities outside hazardous areas

Priority 4, 33(c): resilience of new facilities

\section{SDGs}

Target 11.5: reduce the number of deaths and

the number of people affected and

substantially decrease direct economic losses

Target 11.b: integrated policies and plans towards inclusion, resource efficiency, mitigation and adaptation to climate change, resilience to disasters, and develop and implement...holistic disaster risk management at all levels

Target 11.7: provide universal access to safe, inclusive and accessible, green and public spaces.

Targe 11.a: support positive economic/social/environmental links between urban/peri-urban/rural areas by strengthening national/regional development planning

Target 11.1: access to adequate, safe and affordable housing

Target 11.c: building sustainable and resilient buildings utilizing local materials.

Priority 4, 32: empowerment of women and people with disabilities to publicly lead and promote gender equity and universal accessibility Priority $4,33(0)$ : the provision of psychological care
Commitment 77: strengthening the resilience of cities and urban settlements, by adopting and implementing integrated age- and gender-responsive policies and plans and ecosystem-based approaches in line with the SFDRR and by mainstreaming holistic and data-informed disaster risk reduction and management at all levels to reduce vulnerabilities and risk

Commitment 78: moving from reactive to more proactive risk-based, all hazards and all of society approaches

Commitment 37: safe, inclusive, accessible, green and quality public spaces;

67: open spaces that contribute to the resilience of cities to disasters and climate change.

Commitments 97, 98, and 106: compact city planning and controlling urban sprawl

69: promoting ecological and social function of land, including coastal areas,

Commitment 31: the right to adequate housing for all

33: housing options that are safe, affordable, and accessible for members of different income groups of society;

34: equitable /affordable access to sustainable basic physical and social infrastructure for all, including affordable serviced land, housing, etc.;

46: affordable and sustainable housing and housing finance,

Commitment 26: urban and rural development that is people-centered, protects the planet, and is age- and gender-responsive and supports the realization of all human rights and fundamental freedoms... empowering all individuals and communities while enabling their full and meaningful participation;

41: meaningful participation in decision-making, planning and follow up processes for all, as well as civic engagement and co-provisions and co-production

42: strengthening the interface for all dialogues, including through age- and genderresponsive approaches and with particular attention to contributions from all segments of society, including men and women, children and youth, older persons and persons with disability. 
Table 2 Achievement of key aims/goals from the three frameworks in post-GEJE recovery in Tohoku

\begin{tabular}{|c|c|c|c|}
\hline & Achieved & Partially achieved & Not addressed \\
\hline \multirow[t]{2}{*}{ SFDRR } & $\begin{array}{l}\text { Physical reconstruction: } \\
\text { Priority 4, 33(j)/33(k) land-use planning; } \\
\text { Priority 4, 33(l) relocation of critical facilities out } \\
\text { of hazardous areas; } \\
\text { Priority 4, 33(c) resilience of new facilities }\end{array}$ & Priority $4,33(\mathrm{o})$ : provision of psychological care & $\begin{array}{l}\text { Priority 4, 32: empowerment of women and people with disabilities to } \\
\text { publicly lead and promote gender equity and universal accessibility }\end{array}$ \\
\hline & $\begin{array}{l}\text { Tsunami-affected areas } \\
\text { a)Reduce disaster mortality; } \\
\text { b)Reduce the number of affected people; } \\
\text { c) Reduce direct economic losses from disaster }\end{array}$ & & $\begin{array}{l}\text { Nuclear disaster-affected areas } \\
\text { a)Reduce disaster mortality; } \\
\text { b)Reduce the number of affected people; } \\
\text { c) Reduce direct economic losses from disaster [27] }\end{array}$ \\
\hline \multirow[t]{2}{*}{ SDGs } & $\begin{array}{l}\text { Target 11.5: reduce number of deaths, people } \\
\text { affected and direct economic losses caused by } \\
\text { disasters } \\
\text { 11.b, increase resilience to disasters, }\end{array}$ & & \\
\hline & $\begin{array}{l}\text { Target 11.1: provide access for all to adequate, safe } \\
\text { affordable housing } \\
\text { Target 11.2: sustainable transport systems }\end{array}$ & $\begin{array}{l}\text { Target 11.a: support positive economic, social and } \\
\text { environmental links between urban, peri-urban } \\
\text { and rural areas by strengthening national and } \\
\text { regional development planning } \\
\text { Target 11.c: building sustainable and resilient } \\
\text { buildings utilizing local materials. } \\
11.3 \text { inclusive and sustainable urbanization and } \\
\text { capacity for participatory, integrated and } \\
\text { sustainable settlements, }\end{array}$ & \\
\hline \multirow[t]{2}{*}{ NUA } & $\begin{array}{l}\text { Commitment 31: the right to adequate housing } \\
\text { for all } \\
34 \text { : equitable /affordable access to sustainable } \\
\text { basic physical and social infrastructure for all, } \\
\text { including affordable serviced land, housing, etc.; } \\
46 \text { : affordable and sustainable housing and } \\
\text { housing finance }\end{array}$ & $\begin{array}{l}\text { Commitment } 77 \text { : retrofitting all risky housing } \\
\text { stock, to make it resilient to disasters }\end{array}$ & \\
\hline & $\begin{array}{l}\text { 37: safe, inclusive, accessible, green and quality } \\
\text { public spaces } 67 \text { ) open spaces that contribute to } \\
\text { the resilience of cities to disasters and climate } \\
\text { change }\end{array}$ & $\begin{array}{l}\text { Commitments 97, 98, and 106: compact city } \\
\text { planning; control urban sprawl. } \\
69 \text { : promoting ecological and social function of } \\
\text { land, including coastal areas, } \\
\text { 26: empowering all individuals and communities } \\
\text { while enabling their full and meaningful } \\
\text { participation; } \\
\text { 41: meaningful participation in decision-making, } \\
\text { planning and follow up processes for all; civic } \\
\text { engagement and co-provisions and co- } \\
\text { production }\end{array}$ & $\begin{array}{l}\text { Commitment 28: ensuring full respect of the human rights of } \\
\text { refugees, internally displaced persons (not addressed for nuclear } \\
\text { refugees) }\end{array}$ \\
\hline
\end{tabular}


62: addressing the social, economic and spatial

implication of aging populations 